\title{
In Vitro Screening of Indica Rice Genotypes for Drought Tolerance Using Polyethylene Glycol
}

\author{
T. Sabesan* and K. Saravanan
}

\begin{abstract}
Rice (Oryza sativa $\mathrm{L} 2 \mathrm{n}=24$ ), one of the three major food crops of the world, covers 11 per cent of the arable land in the world. One of the main constraints of rice cultivation and production is drought, which affects the vegetative growth rate and grain yield. The present investigation was carried out to study the drought tolerance of 50 indica rice genotypes including 24 modern varieties, 16 rice cultures and ten traditional varieties along with the drought tolerant check varieties PMK 3 and MDU 5. The 50 rice genotypes were screened in in vitro bioassay method by using Polyethylene glycol (PEG $6000 \mathrm{MW}$ ) to assess their seedling response under drought. Drought stress was simulated at four different concentrations namely, $-3.0,-5.0,-7.5$ and -10.0 bars of water potential by dissolving 115 , 196, 235 and 289 grams of PEG 6000 respectively in $1000 \mathrm{ml}$ of distilled water. A control ( 0.0 bar) was maintained using distilled water The experiment was laid in completely randomized design with two replications. Data were recorded on germination percentage, root length, shoot length and root / shoot ratio at four different levels of treatment. Screening of the 50 rice genotypes for tolerance to drought at seedling stage using various concentrations of PEG 6000 resulted in the identification of nine rice genotypes namely, G3, G19, G21, G24, G25, G31, G35, G49 and G50 with tolerance to drought. The in vitro screening of rice seedlings using PEG 6000 can be adjudged as a simple, rapid and preliminary bioassay that can be used in mass screening for evaluating seedling of rice genotypes under drought.
\end{abstract}

Index Terms - Drought, in vitro screening, PEG, Rice

\section{INTRODUCTION}

Drought is one of the major limiting factor that affects rice productivity in Asia [9]. It is estimated that by 2025,15 million hectares of irrigated land and 22 million hectares in Asia will be under physical and economic water scarcity respectively [12].

The percentage of drought affected land in the world has more than doubled since 1970s [4]. Early and rapid root elongation is an important indicator of drought tolerance and root length is more affected than shoot length under drought. Screenings for drought tolerance at seedling stage using osmotic solutions is reported as one of the robust methods to study resistance during germinal phase by [8] and [11]. With this background, the present study was undertaken to evaluate the

Manuscript received September 14, 2016.

*Corresponding author.

T. Sabesan, is serving as Assistant Professor in the Department of Genetics and Plant Breeding, Faculty of Agriculture, Annamalai University, Annamalainagar-608002, TamilNadu India

K. Saravanan, is working as Professor in the Department of Genetics and Plant Breeding, Faculty of Agriculture, Annamalai University, Annamalainagar-608002, TamilNadu, India. drought tolerance of the 50 rice genotypes at seedling stages using polyethylene glycol 6000 (PEG 6000).

\section{MATERIALS AND METHODS}

\section{A. Genetic materials}

Experimental material comprised of fifty genotypes with broad genetic base involving 24 modern varieties, 16 rice cultures and ten traditional varieties along with the drought tolerant check varieties PMK 3 and MDU 5.

\section{B. Laboratory experiment}

The experiment was conducted at the Abiotic Stress Laboratory of Department of Genetics and Plant Breeding, Faculty of Agriculture during August, 2014. The in vitro screening for drought tolerance was carried out using Polyethylene Glycol (PEG $6000 \mathrm{MW}$ ) according to [1]. In germination paper, a horizontal line was drawn at $3 \mathrm{~cm}$ from the top and was marked with 25 points at $1 \mathrm{~cm}$ intervals. Twenty five seeds of each genotype were placed in the marked point on the moistened paper towel, ensuring that the seeds do not touch each other and a moistened second paper towel was carefully placed over the seeds. The paper towels along with a polythene sheet below it were then rolled loosely to form a tube and held with rubber band. The rolls were placed in the containers of different PEG concentration. Drought stress was simulated at four different concentrations namely, $-3.0,-5.0,-7.5$ and -10.0 bars of water potential created by dissolving 115, 196, 235 and 289 grams of PEG 6000 respectively in $1000 \mathrm{ml}$ of distilled water following the method of [2]. A control ( 0.0 bar) was maintained using distilled water. At 10 DAS (Days After Sowing) data were recorded on germination percentage, root length, shoot length and root / shoot ratio at four different levels of treatment. The experiment was laid in completely randomized design with two replications.

\section{RESULTS AND DISCUSSION}

Significant differences were observed under different PEG concentration ( 0.0 control, $-3.0,-5.0,-7.5$ and -10.0 bars) for all the characters under the study.

\section{Effect of water stress on Germination Percentage}

Different levels of water stress induced by PEG had significant effects on the seed germination. The germination capacity significantly varied $(54.50 \%$ in -10.0 bars to $100.00 \%$ in control) between the treatments than the genotypic differences. Out of the 50 genotypes studied 15 recorded 
significant germination per cent in control while only nine genotypes recorded significant germination at 10.0 bars. Among the genotypes tested, seven genotypes namely, ADT 43 (G3), AURC 4 (G19), AURC 6 (G21), AURC 9 (G24), AURC 10 (G25), AURC 16 (G31) and TN 1(G35) recorded significant germination percentage when compared with the control. Moreover, Genotypes ADT 41 (G2), ADT 45(G5) and ADT 47 (G6) were most affected by the osmotic water stress of -10.0 bars and the check variety PMK 3 (G49) and MDU 5 (G50) had highest germination in most of the concentration. The final germination percentage varied between $100 \%$ for the control and $0.00 \%$ for the most concentration of PEG solution. It was observed that decline in germination percentage with decreasing water potential might be due to low hydraulic conductivity of the environment, where PEG 6000 makes water unavailable to seeds, affecting the imbibition processes of the seed which is fundamental for germination [7]. Results of the current study were in agreement with [13], [1] and [8]. The lowest germination percentage was observed at -10.0 bars. This larger reduction with PEG solution could be attributed to high viscosity, where solubility and diffusion of oxygen were reduced compared to control. At water potential -10.0 bars, the rate of germination of the rice genotypes was below $50 \%$ which is similar to the results obtained by [1] and [11]. This may also be the consequence of hampered water and nutrient absorption due to a decreasing water potential of the medium or greatly suppressed cell elongation as a result of the low turgor pressure. Higher rate of germination even under water deficit conditions is a considered as a desirable feature by [7] and [8].

\section{Effect of water stress on root length}

Early and rapid elongation of root is an important indication of drought tolerance. A root system with longer root length at deeper layer is useful in extracting water in upland conditions [5] \& [9]. In the present investigation, the root length also significantly declined with increased external water potential (Table I) and consequently, all treatments caused a decrease in root elongation in all genotypes compared to their controls. Out of the 50 genotypes studied, 22 recorded significant root length in control while only nine genotypes recorded significant root length at 10.0 bars. The mean root length varied from $11.92 \mathrm{~cm}$ (10.0 bars) to $22.26 \mathrm{~cm}$ (Control). The genotype ADT 44 (G4) recorded significant root length in control alone while IR 20 (G18), AURC 7 (G22), AURC 8 (G23), Ranjith (G39), Gayathri (G43), Chomala (G44) and Marathondi (G47) showed tolerance to mild drought (-3.0 bar) stress. Three genotypes namely, AURC 12 (G27), Koduveliyan (G45) and Onamuttan (G46) recorded moderate drought tolerance ( -7.5 bars). Long roots was reported as a component trait for drought tolerance by [1] and [11] as they play a direct role with high penetration ability and have large xylem vessel radii and lower axial resistance to water flux aiding in greater water acquition.

At higher concentration of PEG (-10.0 bar), the genotype AURC 9 recorded highest root length of $22.70 \mathrm{~cm}$ when compared to the control PMK3 $(24.95 \mathrm{~cm})$. The genotype AURC 8 was distinguished from the other population by its marked reduction in root length $(7.30 \mathrm{~cm})$.

\section{Effect of water stress on shoot length}

Though root length is more affected by drought than shoot length, the effect of drought is exhibited mostly on the shoot as well as aerial parts of the plant, which will bear most economic parts of the crops. Hence, the shoot parameters will also help the breeder while selecting the superior genotypes against drought. In the present study, out of the 50 genotypes studied 17 recorded significant shoot length in control while only nine genotypes recorded significant values at 10.0 bars and the shoot length was decreased with an increase in external water stress. However, this retardation was found to be high in AURC 8 (G23) $(3.30 \mathrm{~cm})$ at high concentration of PEG and low in AURC 9 (G24) and AURC 10 (G25) with the shoot length of 14.25 and $12.90 \mathrm{~cm}$, respectively. These genotypes also showed highest individual mean shoot length of 12.78 and $14.29 \mathrm{~cm}$ in all the treatment conducted in the laboratory. These results corroborates with the findings of [1], [8] and [9]. [6] had also observed the retardation in growth of shoot and root length in response to increasing moisture stress under field as well as laboratory condition. In this study, the genotypes BPT 5202 (G9) and TRY 3 (G11) recorded significant value in control alone, while IR 20 (G18), AURC 7 (G22), CO 45 (G33), Savullu samba (G38) and Chenthadi (G48) recorded mild tolerance (-.3.0 bars). The genotype Kullakar (G36) exhibited moderate tolerance (-7.5 bars). Varietal difference for drought tolerance at seedling and vegetative stage has also been reported by $[10]$.

\section{Effect of water stress on root/shoot ratio}

In addition to root and shoot lengths, root to shoot ratio also plays a major role in selecting drought tolerant lines. Genotypes with high root/shoot ratio under drought are much preferred. The present study revealed significant variations for the root/shoot ratio among the genotypes studied. The ratio ranged from 1.05 (G9) to 2.87 (G44) in the control. In treatments, the highest ratio was observed in G44 (3.13) while the lowest ratio was recorded by the genotype G9 (1.09). In control, high root/shoot ratio was exhibited by several genotypes which failed to record the same under drought stress. However, drought tolerant genotypes recorded significant root/shoot ratio under stressed condition. High root to shoot ratio has been reported as a component trait for drought avoidance by [1], [13] - [15].

The results showed that the plants have a high capacity to vary the allocation of nutrients and the activities of different metabolic pathways for producing biomass in both shoots and roots. The studies of [15] revealed that under drought conditions the plasticity of the plants allow increased allocation of several primary metabolites to roots while decreasing allocation to shoots.

\section{CONCLUSION}

In the present study, the results proved the use of PEG 6000 for the experimental control of external water potential as an effective method for studying the effect of water stress on seed germination and seedling growth characters and also showed it as a simple cost effective method to screen large set of germplasm within very less time period and accuracy, which is in accordance with [1], [13] and [14] . However, the experiment 
needs to be augumented by field evaluation methods to validate drought resistant genotypes identified by in vitro screening.

In general, the findings of this study revealed that PEG-induced drought stress reduced germination percentage, shoot and root lengths while increased root/shoot ratio in tolerant genotypes when compared to susceptible ones. This corroborates with the findings of [1], [5], [13]-[15]. Though many factors influence the drought tolerance of crops, these factors are not independent, but interact with one another. Hence, to study crop resistance to drought, attention should not only be paid to identifying typical characteristics, but also to their relationship and interaction of those characteristics.

It has been reported that PEG-induced osmotic stress can cause hydrolysis of storage compounds that further lower the internal osmotic potentials of the seed [3]. In this study, all the genotypes showed significant differences at various concentrations, but the genotypes namely AURC 9 (G24), AURC 10 (G25), AURC 16 (G31) and TN1 (G35) are identified as drought tolerant lines. Hence, the system used in this study would be a simple, rapid and cost effective method for screening seedling traits of large set of germplasm for drought tolerance.

\section{REFERENCES}

[1] M. Govindaraj, P. Shanmugasundaram, P. Sumathi and A .R. Muthiah. "Simple, rapid and cost effective screening method for drought resistant breeding in Pearl millet," Electronic J. Pl. Breed., vol. 1, no. 4, pp 590-599, 2010.

[2] A. Hadas, "Water uptake and germination of leguminous seeds under changing external water potential in osmoticum solution," J. Exp. Bot., vol. 27, pp. 480-489, 1976. http://dx.doi.org/10.1093/jxb/27.3.480

[3] C. R. Hampson and G.M. Simpson, "Effects of temperature, salt and osmotic potential on early growth of wheat (Triticum aestivum L.) germination,” Can. J. Bot., vol. 68, pp 524-528, 1990. http://dx.doi.org/10.1139/b90-072

[4] N. Isendahl and G. Schmidt. (July 2006). Drought in the Mediterranean. WWF policy proposals. A WWF Report, Madrid pp. 1-41. Available: http:// assets.panda.org/downloads/wwf_drought_med_report_2006.pdf.

[5] Y. J. Kim, S. Shanmugasundaram, S.J. Yun, H.K. Park and M. S. Park, "A simple method of seedling screening for drought tolerance in soybean," Korean J Crop Sci, vol. 46, pp 284-288, 2011.

[6] D. W. Lawlor, "Absorption of polyethylene glycols by plants and their effects on plant growth," New Phytol., vol. 69, pp. 501-513, 1970. http://dx.doi.org/10.1111/j.1469-8137.1970.tb02446.x

[7] A.K.S. Lobato, R.C.L. Costa, C.F. Oliveira Neto, B.G. Santos Filho, M.C Gonçalves-Vidigal, P.S. Vidigal Filho, C.R. Silva, F.J.R. Cruz, P.M.P. Carvalho, P.C.M. Santos and A.Gonel, "Consequences of the water deficit on water relations and symbiosis in Vigna unguiculata cultivars," Plant, Soil and Environment., vol. 5, pp. 139- 145, 2009.

[8] P. Osman Basha, G. Sudarsanan, M. Madhu Sudhana Reddy and N. Siva Sankar, "Effect of PEG induced water stress on germination and seedling development of tomato germplasm," Intl. J. Recent Scientific Res., vol. 6, no. 5, pp. 4044-4049, May 2015.

[9] V. Pandey and A. Shukla, "Acclimation and tolerance strategies of rice under drought stress," Rice Sci., vol. 22, no. 4, pp 14-161, April 2015. http://dx.doi.org/10.1016/j.rsci.2015.04.001

[10] G. Pantuwan, S. Fukai, M. Cooper, S. Rajatasereekul and J.C. O'Toole, "Yield response of rice (Oryza sativa L.) genotypes to different types of drought under rainfed lowlands," Field Crops Res., vol. 73, pp 181-200, 2002 . http://dx.doi.org/10.1016/S0378-4290(01)00195-2

[11] B. Piwowarczyk, I. Kaminska and W. Rybinski, "Influence of PEG generated osmotic stress on shoot regeneration and some biochemical parameters in Lathyrus culture," Czech J. Genet. Plant Breed., vol. 50, no, 2, pp 77-83, 2014.
[12] R. Prasad, "Aerobic rice systems," Adv. in Agron., vol. 111, pp. 207-247, 2011.

http://dx.doi.org/10.1016/B978-0-12-387689-8.00003-5

[13] L. Radhouane, "Response of Tunisian autochthonous pearl millet (Pennisetum glaucum (L.) R. Br.) to drought stress induced by polyethylene glycol (PEG) 6000," African J. of Biotech., vol. 6, pp. 1102-1105, 2007.

[14] L. Van den Berg and Y. J. Zeng, "Response of South African indigenous grass species to drought stress induced by polyethylene glycol (PEG) 6000," Afr. J. Bot,, vol. 72, pp. 284-286, 2006. http://dx.doi.org/10.1016/j.sajb.2005.07.006

[15] W. Xu, K. Cui, A. Xu, L. Nie, J. Huang and S. Peng, "Drought stress condition increases root to shoot ratio via alteration of carbohydrate partitioning and enzymatic activity in rice seedlings," Acta Physiol Plant, vol. 37 , no. 9, pp. 1-11, Jan. 2015 .

http://dx.doi.org/10.1007/s11738-014-1760-0

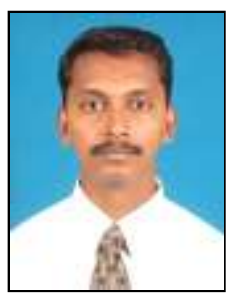

T. Sabesan is born on $16^{\text {th }}$ June, 1977 at Mayiladuthurai. He completed his under graduation in the field of agriculture during 1998 and pursued his post graduation in M.Sc.(Ag.) Genetics and Plant Breeding at Faculty of Agriculture, Annamalai University, TamilNadu, India during 2000. He was awarded Dr. M.S. Swaminathan Endowment Gold Medal for Top Ranking Student in M.Sc.(Ag.) Genetics and Plant Breeding. He cleared National Eligibility Test (NET) for Lecturership in the field of Genetics during 2001. In 2005, he completed his Ph.D dissertation on the genetics of quality traits in rice.

At present, he is working as Assistant Professor in the Department of Genetics and Plant Breeding, Faculty of Agriculture, Annamalai University, TamilNadu, India. He has 17 years of research experience and 15 years of teaching experience at both UG and PG levels. From his Ph.D research work he has nominated a rice culture AURC0205-1 for AICRIP trials, which was ranked $5^{\text {th }}$ at national level. Currently he is involved in research on abiotic stress tolerance in rice and pulses. He has guided 6 M.Sc (Ag.) Genetics and Plant Breeding students.

Dr. Sabesan Thayumanavan has served as Advisor for Literary Committee and Editor of the College Magazine. He also served as Care Taker of 6TN (BN) NCC (National Cadet Corps); Member of Sports and Cultural committees of the Faculty of Agriculture; Member of Student Counseling and Admission committee for Professional courses of the Annamalai University since 2013. Organized UGC-SAP sponsored National Seminar on "Abiotic Stress and Crop Improvement (ASCI 2013)" on 24th Jan. 2013. He is the Life Member of "Association of Rice Research Workers (ARRW), Cuttack, Orissa, "Indian Society of Plant Genetic Resources, New Delhi and "Indian society of Plant Breeders, TNAU, Coimbatore, TamilNadu". He served as Principal/Co-principal Investigator in 5 Major Research Projects. He has been conferred with the 'Outstanding Humanitarian Award' for active involvement in Flood Relief Activities of Cuddalore district of TamilNadu as the President of Rotary club of Chidambaram Temple Town during 2015. To his credit, he has published more than 20 research papers in scientific journals of repute and authored 3 text books and a book chapter: T. Sabesan, Chapter 16. Small Millets..In: Breeding, Biotechnology \& Seed Production of Field Crops. Eds. Bidhan Roy, Asit Kumar Basu \& Asit B. Mandal. New India Publishing Agency. Pp 501-551, 2013

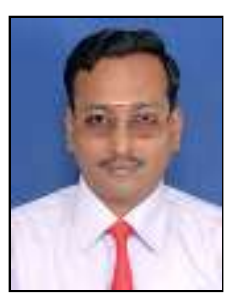

K. Saravanan is born on 5th July, 1971 at Attur. He completed his under-graduation during 1993 and has done post-graduation in M.Sc.(Ag.) Genetics and Plant Breeding at Faculty of Agriculture, Annamalai University, TamilNadu, India during 1995. He was awarded Dr. Sivasubramanian Endowment Gold Medal for highest marks in Quantitative Genetics. He has completed his Ph.D research work in Triple Test Cross analysis in bhendi during 2002.

Currently, he is serving as Professor of Genetics and Plant Breeding at Faculty of Agriculture, Annamalai University, TamilNadu, India. He has 22 years of research experience and 20 years of teaching experience both at UG and PG levels. His research interest include heterosis breeding in vegetables 
and quantitative genetics. He has guided 4 Ph.D. students and 11 Post graduate students.

Dr. Saravanan Kannapiran has served as Editor of Annamalai University research Journal for Agriculture (AUJA) during the academic year 2014-2015. $\mathrm{He}$ is serving as Doctoral Committee member of Vellore Institute of Technology (VIT), TamilNadu. He is serving as member of Admission Committee for Professional Courses of Annamalai University since 2014.

$\mathrm{He}$ is serving as the Secretary of Rotary Club of Chidambaram Temple Town for the year 2016-2017. He has published more than 65 research papers in reputed scientific journals and has authored/edited three books.

TABLE I

SCREENING Of 50 Rice GENOTyPes For Drought TolerANCE At SEEDLING Stage Using Peg 6000

\begin{tabular}{|c|c|c|c|c|c|}
\hline \multirow{2}{*}{ Genotype code } & \multicolumn{5}{|c|}{ Germination $\%$} \\
\cline { 2 - 6 } & \multicolumn{4}{|c|}{ External water potential (bars) } \\
\cline { 2 - 6 } & Control & -3 & -5 & -7.5 & -10 \\
\hline G 1 & 95.00 & 68.50 & 51.50 & 39.00 & 26.55 \\
\hline G 2 & 95.50 & 66.60 & 49.00 & 34.50 & 0.00 \\
\hline G 3 & $100.00^{* *}$ & $84.50^{* *}$ & $79.50^{* *}$ & $67.00^{* *}$ & $58.50^{* *}$ \\
\hline G 4 & 97.50 & 67.50 & 56.50 & 43.00 & 34.50 \\
\hline G 5 & 94.50 & 63.00 & 51.50 & 43.50 & 0.00 \\
\hline G 6 & 96.50 & 65.50 & 55.50 & 36.50 & 0.00 \\
\hline G 7 & 94.50 & 62.50 & 50.50 & 34.50 & 24.50 \\
\hline G 8 & $98.50^{* *}$ & 60.50 & 53.00 & 29.00 & 22.00 \\
\hline G 9 & $100.00^{* *}$ & $82.50^{* *}$ & 50.50 & 41.00 & 33.00 \\
\hline G 10 & $100.00^{* *}$ & 63.00 & 48.40 & 39.00 & 27.00 \\
\hline G 11 & $100.00^{* *}$ & $87.00^{* *}$ & $74.50^{* *}$ & 40.00 & 24.50 \\
\hline G 12 & $98.50^{*}$ & $83.50^{* *}$ & $77.00^{* *}$ & $67.00^{* *}$ & 21.00 \\
\hline G13 & 96.50 & $85.50^{* *}$ & $75.50^{* *}$ & 42.00 & 21.00 \\
\hline G 14 & 94.50 & 68.00 & 59.00 & 45.00 & 33.00 \\
\hline G 15 & 97.50 & 85.00 & $77.00^{* *}$ & $65.00^{* *}$ & 35.00 \\
\hline G 16 & 95.50 & 59.50 & 52.00 & 39.00 & 27.00 \\
\hline G 17 & 95.50 & 67.50 & 54.50 & 41.00 & 29.50 \\
\hline G 18 & 95.50 & 75.50 & 51.00 & 44.00 & 37.00 \\
\hline G 19 & $98.50^{*}$ & $88.00^{* *}$ & $79.50^{* *}$ & $74.50^{* *}$ & $66.50^{* *}$ \\
\hline G 20 & 95.50 & 59.50 & 48.50 & 41.00 & 24.30 \\
\hline G 21 & $98.50^{*}$ & $84.50^{* *}$ & $79.50^{* *}$ & $67.00^{* *}$ & $58.50^{* *}$ \\
\hline G 22 & 94.00 & 68.00 & 58.50 & 45.00 & 33.00 \\
\hline G 23 & 93.00 & 65.50 & 52.50 & 41.00 & 28.50 \\
\hline G 24 25 & $98.50^{*}$ & $82.50^{* *}$ & $77.50^{* *}$ & $71.50^{* *}$ & $67.00^{* *}$ \\
\hline G 29 & $100.00^{* *}$ & $87.50^{* *}$ & $79.50^{* *}$ & $71.50^{* *}$ & $62.50^{* *}$ \\
\hline 98.45 & 65.50 & 57.00 & 44.00 & 35.00 \\
\hline
\end{tabular}

\begin{tabular}{|c|c|c|c|c|c|}
\hline \multirow{3}{*}{ Genotype code } & \multicolumn{5}{|c|}{ Germination \% } \\
\hline & \multicolumn{5}{|c|}{ External water potential (bars) } \\
\hline & Control & -3 & -5 & -7.5 & -10 \\
\hline G 31 & $98.60^{*}$ & $85.50 * *$ & $78.00^{* * *}$ & $64.50 * *$ & $54.50 * *$ \\
\hline G 32 & $100.00 * *$ & $81.50^{* *}$ & 55.00 & 42.00 & 29.70 \\
\hline G 33 & 94.50 & 70.00 & 58.50 & 47.00 & 34.50 \\
\hline G 34 & 97.50 & 67.50 & 57.00 & 44.40 & 36.90 \\
\hline G 35 & $100.00 * *$ & $92.50^{* *}$ & $87.00^{\text {** }}$ & $84.00^{* *}$ & $77.50^{* *}$ \\
\hline G 36 & 92.50 & 68.50 & 61.50 & 49.00 & 36.50 \\
\hline G 37 & 95.50 & 63.50 & 51.00 & 44.50 & 31.00 \\
\hline G 38 & 95.50 & 67.00 & 53.00 & 42.50 & 33.00 \\
\hline G 39 & 94.00 & 62.50 & 57.00 & 45.50 & 35.50 \\
\hline G 40 & 94.00 & 71.50 & 58.00 & 46.50 & 34.50 \\
\hline G 41 & 95.50 & 67.00 & 58.00 & 47.50 & 35.50 \\
\hline G 42 & 94.50 & 62.50 & 48.50 & 31.00 & 22.50 \\
\hline G 43 & 97.50 & $83.50^{* *}$ & $78.00^{* * *}$ & 49.00 & 36.00 \\
\hline G 44 & 96.50 & 62.50 & 50.50 & 41.00 & 33.00 \\
\hline G 45 & 97.50 & 70.50 & 61.00 & 50.00 & 32.00 \\
\hline G 46 & 98.45 & 72.50 & 51.00 & 42.00 & 34.00 \\
\hline G 47 & 97.50 & 84.50 ** & 53.00 & 41.00 & 35.00 \\
\hline G 48 & 98.45 & 71.0 & 52.00 & 44.00 & 36.50 \\
\hline G 49 & $100.00 * *$ & $92.50^{* * *}$ & $89.50 * *$ & $86.50 * *$ & $79.50 * *$ \\
\hline G 50 & $100.00 * *$ & $90.50^{* *}$ & $88.50^{* * *}$ & 85.50 *** & 77.00 *** \\
\hline Treatment mean & 96.70 & 73.59 & 61.15 & 48.44 & 35.32 \\
\hline $\mathrm{CD}(0.05)$ & 1.32 & 1.89 & 1.97 & 5.81 & 2.17 \\
\hline $\mathrm{CD}(0.01)$ & 1.76 & 2.52 & 2.62 & 7.74 & 2.89 \\
\hline SEd & 0.66 & 0.94 & 0.98 & 2.89 & 1.08 \\
\hline
\end{tabular}

G 1 -ADT-40, G 2-ADT-41, G 3-ADT-43, G 4-ADT-44, G 5-ADT-45, G 6- ADT -47, G 7-ADT-50, G 8-PY-1, G 9-BPT 5202, G 10-BPT 5204, G 11-TRY-3, G 12-AURC-1, G13-AURC-2, G 14-CSR-36, G 15-AURC-3, G 16-ASD-19, G 17-MTU 1010, G 18-IR 20, G 19-AURC-4, G 20-AURC-5, G 21-AURC-6, G 22-AURC-7, G 23-AURC-8, G 24-AURC 9, G 25-AURC-10, G 26-AURC-11, G 27-AURC-12, G 28-AURC-13, G 29-AURC-14, G 30-AURC-15, G 31-AURC-16, G 32-CO-43, G 33-CO-45, G 34-Poongkar, G 35-TN-1, G 36-Kullakar, G 37-Kichedi samba, G 38-Savullu samba, G 39-Ranjith, G 40-Amman, G 41-Basmati, G 42-Jalakara ponni, G 43-Gayathri, G 44-Chomala, G 45-Koduveliyan, G 46-Onamuttan, G 47-Maranthondi, G 48-Chenthadi, G 49-PMK-3, G 50-MDU-5 
TABLE I (CONTD..) SCREening Of 50 Rice Genotypes For Drought Tolerance At SEedling Stage Using Peg 6000

\begin{tabular}{|c|c|c|c|c|c|c|c|c|c|c|c|c|c|c|c|}
\hline \multirow{3}{*}{$\begin{array}{l}\text { Genotype } \\
\text { code }\end{array}$} & \multicolumn{5}{|c|}{ Root length } & \multicolumn{5}{|c|}{ Shoot length } & \multicolumn{5}{|c|}{ Root/shoot ratio } \\
\hline & \multicolumn{5}{|c|}{ External water potential (bars) } & \multicolumn{5}{|c|}{ External water potential (bars) } & \multicolumn{5}{|c|}{ External water potential (bars) } \\
\hline & Control & -3 & -5 & -7.5 & -10 & Control & -3 & -5 & -7.5 & -10 & Control & -3 & -5 & -7.5 & -10 \\
\hline G 2 & 13.40 & 12.95 & 12.00 & 10.85 & 0.00 & 8.65 & 6.80 & 5.50 & 4.75 & 0.00 & 1.55 & 1.90 & 2.18 & $2.28 * *$ & 0.00 \\
\hline G 3 & 20.65 & 17.80 & 15.60 & 13.20 & 10.85 & 12.40 & 11.60 & 10.25 & 7.45 & 5.50 & 1.46 & $2.18^{* *}$ & $2.33 * *$ & $2.50 * *$ & $1.97 * *$ \\
\hline G 6 & 14.25 & 11.80 & 13.85 & 13.35 & 0.00 & 9.55 & 8.30 & 3.00 & 7.20 & 0.00 & 1.49 & 1.42 & 1.62 & 1.85 & 0.00 \\
\hline G 7 & 17.03 & 14.40 & 14.00 & 12.15 & 10.30 & 9.25 & 6.80 & 6.45 & 6.00 & 5.50 & 1.84 & 1.80 & 2.17 & 2.03 & 1.77 \\
\hline G 8 & 19.80 & 15.40 & 13.90 & 12.00 & 10.25 & 10.45 & 9.60 & 7.30 & 6.50 & 5.80 & 1.89 & 1.60 & 1.90 & 1.85 & 1.77 \\
\hline G 9 & 14.65 & 13.55 & 17.55 & 16.85 & 11.55 & $13.90^{*}$ & 12.50 & 8.10 & 9.70 & 7.20 & 1.05 & 1.08 & 2.17 & 1.74 & 1.60 \\
\hline G13 & 20.75 & 16.80 & 10.25 & 10.80 & 8.25 & 10.50 & 7.50 & 7.05 & 6.40 & 5.80 & $2.20 * *$ & 1.46 & 1.45 & 1.69 & 1.42 \\
\hline G 14 & 19.95 & 18.95 & 16.95 & 13.50 & 10.60 & 11.20 & 10.15 & 8.30 & 6.95 & 5.20 & 1.78 & 1.87 & 2.04 & 1.94 & 1.54 \\
\hline G 15 & 16.20 & 11.95 & 10.85 & 9.30 & 8.90 & 8.80 & 8.65 & 7.80 & 6.80 & 4.30 & 1.84 & 1.38 & 1.39 & 1.37 & 1.59 \\
\hline G 16 & 22.50 & 19.50 & 15.45 & 13.15 & 11.10 & 13.35 & 11.15 & 10.15 & 8.85 & 7.25 & 1.69 & 1.75 & 1.52 & 1.49 & 1.53 \\
\hline G 17 & 23.00 & 17.65 & 16.90 & 14.80 & 12.50 & 11.85 & 11.50 & 9.25 & 9.15 & 7.20 & $2.19^{*}$ & 1.53 & 1.83 & 1.62 & 1.74 \\
\hline G 18 & $24.75^{* *}$ & $22.15^{* *}$ & 14.45 & 12.21 & 8.70 & 10.45 & $13.05^{* *}$ & 8.85 & 9.55 & 7.10 & 1.85 & 1.70 & 1.63 & 1.28 & 1.23 \\
\hline G 19 & $29.30^{* *}$ & $24.30^{* * *}$ & $22.65 * *$ & $24.00 * *$ & $15.90^{* * *}$ & $15.85 * *$ & $13.90 * *$ & $11.76^{* * *}$ & $11.00^{* *}$ & $10.30^{* *}$ & 1.55 & $2.24 * *$ & 1.93 & $2.18^{*}$ & $2.04 * *$ \\
\hline G 20 & $23.40^{*}$ & 18.80 & 16.60 & 15.80 & 12.30 & 13.40 & 11.80 & 10.85 & 9.20 & 6.85 & 1.75 & 1.59 & 1.53 & 1.72 & 1.80 \\
\hline G 21 & $26.85^{* *}$ & $25.70^{* * *}$ & $20.95 * *$ & $20.85^{* *}$ & $18.60^{* *}$ & $15.50^{* * *}$ & $14.30 * *$ & $11.85^{* *}$ & $11.00 * *$ & $9.95^{* *}$ & 1.73 & $2.12^{*}$ & 1.77 & 1.90 & $1.87 *$ \\
\hline G 27 & 22.80 & $21.20^{* *}$ & $19.30^{*}$ & $21.80^{* *}$ & 9.70 & 11.25 & 10.40 & 10.20 & 8.30 & 3.60 & 2.03 & 2.04 & 1.89 & $2.19 *$ & 1.42 \\
\hline G 28 & 21.65 & 20.45 & 17.55 & 16.70 & 12.40 & 11.40 & 10.85 & 10.85 & $10.15^{*}$ & 6.60 & 1.58 & 1.67 & 1.65 & 1.33 & 1.43 \\
\hline G 29 & $25.40^{* *}$ & $22.95^{* * *}$ & $21.05 * *$ & 15.55 & 10.66 & $15.00 * *$ & 11.85 & 10.30 & 8.95 & 5.50 & 1.90 & 1.88 & 1.62 & 1.65 & $1.88^{*}$ \\
\hline G 30 & $29.40^{* *}$ & $25.85^{* *}$ & $25.55 * *$ & 14.65 & 9.85 & 10.65 & 8.90 & 8.80 & 7.90 & 7.40 & 1.69 & 1.94 & 2.04 & 1.74 & 1.33 \\
\hline
\end{tabular}

G 1 -ADT-40, G 2-ADT-41, G 3-ADT-43, G 4-ADT-44, G 5-ADT-45, G 6- ADT -47, G 7-ADT-50, G 8-PY-1, G 9-BPT 5202, G 10-BPT 5204, G 11-TRY-3, G 12-AURC-1, G13-AURC-2, G 14-CSR-36, G 15-AURC-3, G 16-ASD-19, G 17-MTU 1010, G 18-IR 20, G 19-AURC-4, G 20-AURC-5, G 21-AURC-6, G 22-AURC-7, G 23-AURC-8, G 24-AURC 9, G 25-AURC-10, G 26-AURC-11, G 27-AURC-12, G 28-AURC-13, G 29-AURC-14, G 30-AURC-15 
TABLE I (CONTD..)

SCREEning OF 50 Rice Genotypes For Drought Tolerance At SEedling Stage Using Peg 6000

\begin{tabular}{|c|c|c|c|c|c|c|c|c|c|c|c|c|c|c|c|}
\hline \multirow{3}{*}{$\begin{array}{l}\text { Genotype } \\
\text { code }\end{array}$} & \multicolumn{5}{|c|}{ Root length } & \multicolumn{5}{|c|}{ Shoot length } & \multicolumn{5}{|c|}{ Root/Shoot ratio } \\
\hline & \multicolumn{5}{|c|}{ External water potential (bars) } & \multicolumn{5}{|c|}{ External water potential (bars) } & \multicolumn{5}{|c|}{ External water potential (bars) } \\
\hline & Control & -3 & -5 & -7.5 & -10 & Control & -3 & -5 & -7.5 & -10 & Control & -3 & -5 & -7.5 & -10 \\
\hline G 31 & $28.40^{* *}$ & $26.80^{* * *}$ & $24.60^{* *}$ & $22.45^{* *}$ & $20.80^{* *}$ & $15.80 * *$ & $13.50^{* *}$ & $12.65^{* *}$ & $11.90 * *$ & $10.50 * *$ & $2.76^{* * *}$ & $2.90 * *$ & $2.90 * *$ & 1.85 & $1.94 * *$ \\
\hline G 32 & 21.40 & 18.85 & 17.40 & 16.80 & $16.50^{* *}$ & 10.60 & 9.15 & 9.00 & 8.70 & 6.20 & 1.80 & 1.99 & 1.94 & 1.89 & $1.98 * *$ \\
\hline G 33 & $23.80^{* *}$ & 19.85 & 18.40 & 17.00 & 12.40 & $14.70^{* *}$ & $13.95^{* *}$ & 10.35 & 8.95 & 5.50 & 2.02 & 2.06 & 1.93 & 1.93 & $2.66 * *$ \\
\hline G 34 & 15.90 & 14.85 & 12.8 & 12.40 & 9.80 & 12.40 & 11.95 & 6.95 & 8.25 & 7.55 & 1.62 & 1.42 & 1.78 & 1.90 & 1.30 \\
\hline G 35 & $27.95^{* *}$ & $24.00^{* * *}$ & $22.50^{* * *}$ & $20.65^{* *}$ & $16.65^{* *}$ & $16.90 * *$ & $15.80^{* *}$ & $15.40^{* *}$ & $14.95^{* *}$ & $12.65^{* *}$ & 1.95 & $2.64 * *$ & $2.70 * *$ & $2.71 * *$ & $2.25 * *$ \\
\hline G 36 & 21.92 & 18.50 & 16.50 & 15.50 & 12.50 & $14.60 * *$ & $12.50^{*}$ & $11.35^{*}$ & $10.60 * *$ & 4.70 & $2.19 * *$ & 1.52 & 1.46 & 1.38 & 1.32 \\
\hline G 37 & 20.50 & 20.15 & 17.90 & 17.00 & 12.60 & 10.50 & 9.40 & 9.00 & 9.30 & 6.20 & 1.50 & 1.48 & 1.45 & 1.46 & $2.66 * *$ \\
\hline G 38 & 20.85 & 19.15 & 16.90 & 12.40 & 9.70 & $16.55^{* *}$ & $14.25^{* *}$ & 9.90 & 9.70 & 5.40 & $2.74 * *$ & $2.14^{*}$ & 1.99 & 1.83 & 1.75 \\
\hline G 39 & $23.80^{* *}$ & $20.90 * *$ & 18.15 & 17.10 & 9.95 & 10.80 & 9.35 & 8.35 & 7.40 & 6.40 & 1.26 & 1.34 & 1.71 & 1.28 & 1.80 \\
\hline G 40 & 21.25 & 18.80 & 17.25 & 16.65 & 11.00 & 11.50 & 9.05 & 9.00 & 8.70 & 6.85 & 1.62 & 1.68 & 1.80 & 1.69 & 1.55 \\
\hline G 41 & 13.55 & 12.40 & 11.75 & 10.05 & 9.05 & 8.70 & 8.05 & 7.30 & 6.45 & 5.90 & 1.85 & 2.08 & 1.92 & 1.91 & 1.61 \\
\hline G 42 & 14.85 & 13.45 & 11.40 & 9.50 & 9.10 & 7.65 & 6.85 & 6.05 & 6.05 & 5.45 & 1.56 & 1.54 & 1.61 & 1.56 & 1.53 \\
\hline G 43 & 22.55 & $21.15^{* *}$ & 18.10 & 15.10 & 12.40 & 8.05 & 6.75 & 6.60 & 6.70 & 6.30 & 1.94 & 1.96 & 1.88 & 1.57 & 1.67 \\
\hline G 44 & $24.90^{* *}$ & $22.30^{* *}$ & 17.10 & 14.10 & 11.30 & $14.80^{* *}$ & $13.55^{* *}$ & $13.30^{* *}$ & 9.50 & $8.90^{* *}$ & $2.80 * *$ & $3.13 * *$ & $2.74 * *$ & $2.25 * *$ & 1.67 \\
\hline G 45 & $28.80^{* * *}$ & $27.50^{* * *}$ & $23.35^{* *}$ & $23.30 * *$ & 12.60 & 10.50 & 10.40 & 8.65 & 8.60 & 7.20 & 1.68 & 1.65 & 1.29 & 1.48 & 1.27 \\
\hline G 46 & $26.45^{* * *}$ & $25.30 * *$ & $24.25^{* *}$ & $22.60 * *$ & 12.80 & 11.15 & 10.20 & 9.55 & 9.15 & 7.20 & 1.28 & 1.24 & 1.84 & 1.50 & 1.75 \\
\hline G 47 & $24.40^{* * *}$ & $22.05^{* *}$ & 18.00 & 15.50 & 12.25 & 11.15 & 9.85 & 8.90 & 8.60 & 7.30 & $2.37 * *$ & $2.48 * *$ & 1.71 & 1.75 & 1.78 \\
\hline G 48 & $28.80^{* *}$ & $27.25^{* *}$ & 17.25 & 12.90 & 8.70 & $14.40 * *$ & $12.65^{*}$ & 9.60 & 7.65 & 6.35 & 2.00 & $2.24 * *$ & 2.02 & 1.80 & 1.68 \\
\hline G 49 & $27.50^{* *}$ & $26.50 * *$ & $26.50^{* *}$ & $26.00 * *$ & $24.95^{* *}$ & $17.00 * *$ & $15.80^{* *}$ & $15.50 * *$ & $14.85^{* *}$ & $14.25^{* *}$ & 1.65 & 2.15 & $2.18^{* *}$ & $2.31 * *$ & $1.97 * *$ \\
\hline G 50 & $26.95^{* *}$ & $25.55^{* *}$ & $24.50^{* * *}$ & $22.50 * *$ & $19.50^{* *}$ & $15.70 * *$ & 11.60 & $11.50 *$ & $11.00^{* *}$ & $10.65^{* *}$ & 1.98 & $2.24 * *$ & $2.54 * *$ & $2.47 * *$ & $2.03 * *$ \\
\hline $\begin{array}{c}\text { Treatment } \\
\text { mean }\end{array}$ & 22.26 & 19.76 & 17.68 & 16.02 & 11.92 & 12.24 & 10.94 & 9.54 & 9.07 & 6.92 & 1.87 & 1.84 & 1.92 & 1.80 & 1.65 \\
\hline $\mathrm{CD}(0.05)$ & 1.09 & 0.70 & 0.95 & 1.09 & 0.92 & 1.59 & 1.31 & 1.44 & 1.08 & 0.84 & 5.86 & 0.17 & 0.17 & 0.21 & 0.14 \\
\hline $\mathrm{CD}(0.01)$ & 1.45 & 0.93 & 1.27 & 1.45 & 1.23 & 2.12 & 1.74 & 1.92 & 1.44 & 1.12 & 7.81 & 0.23 & 0.23 & 0.28 & 0.19 \\
\hline SEd & 0.54 & 0.35 & 0.46 & 0.54 & 0.46 & 0.79 & 0.65 & 0.71 & 0.54 & 0.42 & 2.92 & 0.08 & 0.08 & 0.11 & 0.07 \\
\hline
\end{tabular}

G 31-AURC-16, G 32-CO-43, G 33-CO-45, G 34-Poongkar, G 35-TN-1, G 36-Kullakar, G 37-Kichedi samba, G 38-Savullu samba, G 39-Ranjith, G 40-Amman, G 41-Basmati, G 42-Jalakara ponni, G 43-Gayathri, G 44-Chomala, G 45-Koduveliyan, G 46-Onamuttan, G 47-Maranthondi, G 48-Chenthadi, G 49-PMK-3, G 50-MDU-5 